\title{
GASTROINTESTINAL HELMINTH FAUNA AND HELMINTH COMMUNITIES OF BLEAK (ALBURNUS ALBURNUS, L. 1758) FROM LOWER SECTION OF DANUBE RIVER, BULGARIA
}

\author{
M. CHUNCHUKOVA, D. KIRIN \& D. KUZMANOVA
}

Department of Ecology and Environmental Protection, Agricultural University, Plovdiv, Bulgaria

\section{Summary}

Chunchukova, M., D. Kirin \& D. Kuzmanova, 2019. Gastrointestinal helminth fauna and helminth communities of bleak (Alburnus alburnus, L. 1758) from lower section of Danube River, Bulgaria. Bulg. J. Vet. Med., 22, No 3, 344-352.

The present study presents the results from examinations of bleak's endohelminth species and structure of helminth communities from the Bulgarian part of the Lower Danube River. In 2015 and 2016, on a seasonal manner, 91 specimens of Alburnus alburnus (Linnaeus, 1758) (bleak) were examined with standard techniques for parasites. Five species of parasites: Nicolla skrjabini (Ivanitzky, 1928), Ligula intestinalis (Linnaeus, 1758), Acanthocephalus lucii (Müller, 1776), Pomphorhynchus laevis (Müller, 1776) and Contracoecum microcephalum (Stossich, 1890), larvae were identified. The analysis of the dominant structure of the found parasite species is presented to the component and infracommunities levels. All parasite species were accidental for the parasitic communities of examined fish with the exception of P. laevis and N. skrjabini. P. laevis was a core parasite species and N. skrjabini was a component parasite species for the helminth communities of bleak. The parasite communities of A. alburnus were discussed and compared with previous research data on parasite communities of bleak from River Danube in Bulgaria. New data for helminths and helminth communities of A. alburnus from Danube River (biotope Vetren) and their seasonal occurrence are presented.

Key words: Alburnus alburnus, bleak, Bulgaria Danube, helminths, helminth communities

\section{INTRODUCTION}

Danube River has an important place in European ecological network. The fish community in the shoreline zone of the Danube River in Bulgaria is presented by 44 fish species among which Alburnus alburnus is one of the most abundant (Polačik et al., 2008). Due to its small size, the bleak has no economical importance and is a subject of sport fishing.

Parasites are well acknowledged as sensitive bioindicators for the aquatic ecosystem state (Marcogliese, 2004). Parasite communities are useful indicators of food web structure and biodiversity (Marcogli- 
ese, 2005). Fish parasites communities of A. alburnus from the Bulgarian part of the river were reported in few studies (Kakacheva-Avramova, 1977; Atanasov, 2012; Kirin et al., 2013). The bleak serves as intermediate and final host of helminth species that might affect the status of fish population. The presence of certain helminth species in this abundant fish species may have consequences for the food web and ecosystem structure. Thus, investigation of bleak parasites is useful for aquatic biomonitoring.

This paper presents the results of examinations of bleak gastrointestinal helminth species, new data for structure of helminth communities, and their seasonal changes from the Bulgarian part of the Lower Danube River (village of Vetren).

\section{MATERIALS AND METHODS}

In spring, summer and autumn of 2015 and 2016 fish and fish parasites from the Lower Danube River (village of Vetren, Bulgarian part) were collected and examined. The village of Vetren $\left(44^{0} 133^{\prime} \mathrm{N}\right.$, $27^{\circ} 033^{\prime} \mathrm{E}$ ) is situated on the riverside, in the northeastern part of the Danube Valley.

A total of 91 (spring: 31, summer: 30, autumn: 30) specimens of bleak, Alburnus alburnus (Linnaeus, 1758) from the Danube River were collected and examined in 2015 and 2016. Fish were caught by angling under a permit issued by the Ministry of Agriculture and Food of the Republic of Bulgaria. The scientific and common names of fish hosts were used according to the FishBase database (Fröse \& Pauly, 2017). The examined fish specimens in this study were weighed (mean total weight $13.99 \pm 3.21 \mathrm{~g}$; range 9$24 \mathrm{~g}$ ) and measured (mean total length $12.29 \pm 1.01 \mathrm{~cm}$; range $10.5-15.5 \mathrm{~cm}$ ).
The fish samples were examined for gastrointestinal parasites (incomplete parasitological study) using standard techniques and immediately after their capture. Trematodes were fixed as permanent slides after their staining with acetic carmine, differentiation in $70 \%$ acid ethanol, dehydration in ascending ethanol series, clearing in eugenol and mounting in Canada balm (Bykhovskaya-Pavlovskaya, 1985; Georgiev et al., 1986). The samples were counted and indentified using the keys of Bauer et al. (1981) and Bykhovskaya-Pavlovskaya (1985). Acanthocephalans were examined as temporary mounts in ethanol-glycerin and identified (Petrochenko, 1956; Ergens \& Lom, 1970; Bykhovskaya-Pavlovskaya, 1985). Nematodes were examined as temporary mounts in glycerin (Moravec, 1994).

The dominant structure of the component helminth communities was determined according to the criteria proposed by Kennedy (1993) on the basis of the prevalence $(\mathrm{P} \%)$ : accidental $(\mathrm{P} \%<10)$, component $(\mathrm{P} \%<20)$ and core $(\mathrm{P} \%>20)$ species. The ecological terms prevalence, mean intensity (MI) and mean abundance (MA) were used and calculated as per Bush et al. (1997). Analyses of helminth community structure were carried out during the three seasons and at both infracommunity and component community levels. The seasonal differences were evaluated regardless of the year, thus the data for the two years were combined by seasons. The data were used to calculate the total number of species, mean number of helminths, Shannon diversity index $\left(H^{\prime}\right)$, Brillouin diversity index (HB), Brillouin evenness index ( $\mathrm{HBe})$, Pielou evenness index (E), Simpson dominance index (C) and Berger-Parker dominance index (d) (Kennedy, 1993; Magurran, 1988). 


\section{Statistical analysis}

The Kruskal-Wallis test was used to compare the invasion indices with the established species during the three seasons. To reinforce the argumentation, the results of the two tests were presented. To investigate the relevant factor for the variation (season, year) of the invasion parameters, the nonparametric Friedman test was used. All statistical tests were performed using statistical software (Quantitative Parasitology, version 3, Rozsa et al., 2000; STATISTICA 10.0 program).

\section{RESULTS}

\section{Model fish species}

A total of 91 specimens of bleak, Alburnus alburnus (Linnaeus, 1758) were collected and examined from the Danube River. Alburnus alburnus is estimated as least concern species ( $\mathrm{LC}=$ Least Concern; Anonymous, 2017). Bleak is a freshwater, brackish, benthopelagic, potamodromous fish species. It inhabits open waters of lakes and medium to large rivers. Adult bleaks occur in shoals near the surface. $A$. alburnus larvae live in littoral zone of rivers and lakes, while juveniles leave shores and occupy a pelagic habitat, feeding on plankton, drifting insects or invertebrates fallen on the water surface. The diet of this species includes mainly plankton, as well as crustaceans and insects. Bleak spawns in shallow riffles or along stony shores of lakes and occasionally above submerged vegetation (Fröse \& Pauly, 2017).

\section{Helminth community structure}

Helminth parasites were recorded in 43 bleaks (47.25\%) from the Danube River. Five parasite species presented by 91 specimens were identified: one trematode species, Nicolla skrjabini (Ivanitzky, 1928), one cestode species, Ligula intestinalis (Linnaeus, 1758), two acantocephalans, Acanthocephalus lucii (Müller, 1776), Pomphorhynchus laevis (Müller, 1776) and one nematode species: Contracoecum microcephalum (Stossich, 1890), larvae. All helminth species occurred as adults with the exception of $C$. microcephalum and L. intestinalis (Table 1). N. skrjabini, A. lucii and P. laevis are autogenic species, matured in fish. C. $m i$ crocephalum and $L$. intestinalis are allogenic species, matured in fish-eating birds (Moravec, 1994).

\section{Component community}

In the component community of $A$. alburnus from Danube River, acanthocephalans were presented with the highest number of specimens: 2 species and 50 specimens. Trematodes were presented with one species and 32 specimens. Cestodes were represented by one species with only one specimen. Nematodes were represented by one species and 8 specimens. Pomphorhynchus laevis was a core species $(\mathrm{P} \%=20.88)$. Nicolla skrjabini $(\mathrm{P} \%=19.78)$ was a component parasite species for the helminth communities of bleak. Ligula intestinalis $(\mathrm{P} \%=1.10)$, Acanthocephalus lucii $(\mathrm{P} \%=4.40)$ and Contracoecum microcephalum $(\mathrm{P} \%=4.40)$ were accidental parasite species for the helminth communities of bleak (Table 1).

The parasitic species of A. alburnus from Danube River (biotope Vetren) appeared in all three sampling seasons with the exception of L. intestinalis, A. lucii and $C$. microcephalum. L. intestinalis appeared only in one bleak specimen during the summer. A. lucii and C. microcephalum appeared only in specimens from summer season. In the component community of $A$. alburnus from Danube 
Table 1. Species diversity of helminth parasites of Alburnus alburnus from Danube River

\begin{tabular}{lcccccc}
\hline Helminth species & \multicolumn{7}{c}{$\mathrm{N}=91$} \\
\cline { 2 - 7 } & $\mathrm{n}$ & $\mathrm{p}$ & $\mathrm{P} \%$ & $\mathrm{MA} \pm \mathrm{SD}$ & $\mathrm{MI} \pm \mathrm{SD}$ & Range \\
\hline $\begin{array}{l}\text { Nicolla skrjabini } \\
\text { (Ivanitzky, 1928) }\end{array}$ & 18 & 32 & 19.78 & $0.35 \pm 0.79$ & $1.78 \pm 0.79$ & $1-3$ \\
$\begin{array}{l}\text { Ligula intestinalis } \\
\text { (Linnaeus, 1758), larvae }\end{array}$ & 1 & 1 & 1.10 & $5.91 \pm 23.81$ & $30.22 \pm 46.51$ & 1 \\
$\begin{array}{l}\text { Acanthocephalus lucii } \\
\text { (Müller, 1776) }\end{array}$ & 4 & 8 & 4.40 & $0.09 \pm 0.46$ & $2.0 \pm 1.0$ & $1-3$ \\
$\begin{array}{l}\text { Pomphorhynchus laevis } \\
\text { (Müller, 1776) }\end{array}$ & 19 & 42 & 20.88 & $0.46 \pm 1.11$ & $2.21 \pm 1.44$ & $1-6$ \\
$\begin{array}{l}\text { Contracoecum microcepha- } \\
\text { lum (Stossich, 1890), larvae }\end{array}$ & 4 & 8 & 4.40 & $0.09 \pm 0.48$ & $2.00 \pm 1.22$ & $1-4$ \\
\hline
\end{tabular}

$\mathrm{N}$ - number of examined hosts, $\mathrm{n}$ - number of infected hosts, $\mathrm{p}$ - number of parasites, $\mathrm{P} \%$ - prevalence, MA - mean abundance, MI - mean intensity.

Table 2. Seasonal species diversity of helminth parasites of Alburnus alburnus from Danube River

\begin{tabular}{|c|c|c|c|c|c|c|c|c|c|}
\hline Season & & $\begin{array}{l}\text { Sprin } \\
(\mathrm{N}=3\end{array}$ & & & $\begin{array}{l}\mathrm{Sum} \\
(\mathrm{N}=\mathrm{T}\end{array}$ & & & $\begin{array}{l}\text { Aut } \\
(\mathrm{N}=\end{array}$ & \\
\hline Parasite species & $\mathrm{n} / \mathrm{p}$ & $\mathrm{P} \%$ & $\begin{array}{l}\mathrm{MI} \pm \mathrm{SD} \\
\text { (Range) }\end{array}$ & $\mathrm{n} / \mathrm{p}$ & $\mathrm{P} \%$ & $\begin{array}{l}\mathrm{MI} \pm \mathrm{SD} \\
\text { (Range) }\end{array}$ & $\mathrm{n} / \mathrm{p}$ & $\mathrm{P} \%$ & $\begin{array}{l}\mathrm{MI} \pm \mathrm{SD} \\
\text { (Range) }\end{array}$ \\
\hline Nicolla skrjabini & $13 / 23$ & 41.96 & $\begin{array}{c}1.77 \pm 0.80 \\
(1-3)\end{array}$ & $4 / 8$ & 13.33 & $\begin{array}{c}2.00 \pm 0.71 \\
(1-3)\end{array}$ & $1 / 1$ & 3.33 & $1(1)$ \\
\hline Ligula intestinalis & - & - & - & $1 / 1$ & 3.33 & $1(1)$ & - & - & - \\
\hline $\begin{array}{l}\text { Acanthocephalus } \\
\text { lucii }\end{array}$ & - & - & - & $4 / 8$ & 13.33 & $\begin{array}{c}2 \pm 1 \\
(1-3)\end{array}$ & - & - & - \\
\hline $\begin{array}{l}\text { Pomphorhynchus } \\
\text { laevis }\end{array}$ & $1 / 1$ & 3.23 & $1(1)$ & $8 / 16$ & 26.67 & $\begin{array}{c}2.00 \pm 1.22 \\
(1-4)\end{array}$ & $\begin{array}{l}10 / \\
25\end{array}$ & $\begin{array}{c}28.8 \\
8\end{array}$ & $\begin{array}{c}2.5 \pm 1.57 \\
(1-6)\end{array}$ \\
\hline $\begin{array}{l}\text { Contracoecum } \\
\text { microcephalum }\end{array}$ & - & - & - & $4 / 8$ & 13.33 & $\begin{array}{c}2.00 \pm 1.22 \\
(1-4)\end{array}$ & - & - & - \\
\hline
\end{tabular}

$\mathrm{N}$ - number of examined hosts, $\mathrm{n}$ - number of infected hosts, $\mathrm{p}$ - number of parasites, $\mathrm{P} \%$ - prevalence, MA - mean abundance, MI - mean intensity.

River $P$. laevis had the highest number of specimens (42), with the highest mean intensity during the autumn (2.5 \pm 1.57$). N$. skrjabini exhibited the highest mean summer intensity $(2.0 \pm 0.71)$, but higher during the spring (Table 2).

The highest number of helminth species (5 species) and the highest number of specimens (41) were found in summer season. Dominant species in spring season was $N$. skrjabini, while in summer and autumn season it was P. laevis (Table 3 ).

Significant differences for the three seasons were obtained for Nicolla skrjabini $\quad(\mathrm{P}=0.0004)$, Acanthocephalus lucii ( $\mathrm{P}=0.016), \quad$ Pomphorhynchus laevis $(\mathrm{P}=0.0098)$ and $C$. microcephalum $(\mathrm{P}=0.016)$ with the Kruskal-Wallis test. Significant differences in infestation during the three seasons by means of one-way 
Gastrointestinal helminth fauna and helminth communities of bleak (Alburnus alburnus, L. 1758)...

Table 3. Basic indices of helminth community of Alburnus alburnus from Danube River

\begin{tabular}{|c|c|c|c|c|}
\hline \multirow{2}{*}{ Basic indices } & \multicolumn{3}{|c|}{ Season } & \multirow{2}{*}{$\begin{array}{c}\text { Statistical } \\
\text { significance }\end{array}$} \\
\hline & Spring & Summer & Autumn & \\
\hline Number of helminth species & 2 & 5 & 2 & $\mathrm{P}=0.01$ \\
\hline Number of helminth specimens & 24 & 41 & 26 & $\mathrm{P}=0.02$ \\
\hline H' (Shannon, diversity) & 0.17 & 1.41 & 0.16 & $\mathrm{P}=0.0003$ \\
\hline HB (Brillouin, diversity index) & 0.22 & 0.87 & 0.20 & $\mathrm{P}=0.0003$ \\
\hline HBe (Brillouin, evenness) & 0.13 & 1.26 & 0.13 & $\mathrm{P}=0.0066$ \\
\hline E (Pielou, evenness) & 0.25 & 0.88 & 0.24 & $\mathrm{P}=0.0066$ \\
\hline C (Simpson, dominance) & 0.92 & 0.27 & 0.93 & $\mathrm{P}=0.0004$ \\
\hline d (Berger-Parker Dominance Index) & 0.96 & 0.39 & 0.96 & $\mathrm{P}=0.0001$ \\
\hline Dominant species & N. skrjabini & P. laevis & P. laevis & \\
\hline
\end{tabular}

Table 4. Parameters of the infracommunities of Alburnus alburnus from Danube River

\begin{tabular}{lccccc}
\hline \multirow{3}{*}{ Alburnus alburnus } & \multicolumn{5}{c}{ Number of endohelminth species } \\
\cline { 2 - 6 } & 0 & 1 & 2 & Mean \pm SD & Range \\
\cline { 2 - 6 } & 48 & 40 & 3 & $0.51 \pm 0.56$ & $0-2$ \\
\hline \multirow{3}{*}{ Alburnus alburnus } & \multicolumn{5}{c}{ Number of endohelminth specimens } \\
\cline { 2 - 6 } & \multicolumn{7}{c}{ Total number } & Mean \pm SD & Range & Brillouin's index (HB) \\
\cline { 2 - 6 } & 91 & $1.00 \pm 1.36$ & $1-6$ & $0.43 \pm 0.31$
\end{tabular}

ANOVA were established for Nicolla skrjabini $(\mathrm{P}=0.001)$, Acanthocephalus lucii $(\mathrm{P}=0.035)$, Pomphorhynchus laevis $(\mathrm{P}=0.018)$ and Contracoecum microcephalum $(\mathrm{P}=0.048)$. Friedman Two Way ANOVA showed that the seasons were important for the infestation with $N$. skrjabini $(\mathrm{P}=0.0019)$, A. lucii $(\mathrm{P}=0.018)$, P. laevis $(\mathrm{P}=0.009)$ and $C$. microcephalum $(\mathrm{P}=0.018)$, and for the status of the populations of the species during the three seasons.

\section{Infracommunity}

Species richness in bleak infracommunity ranged from 1 to 2 species. Fourty fish $(43.96 \%)$ were infected with one helminth species and three fish $(3.30 \%)$ - with 2 helminth species. The largest number of helminth specimens established in a single host was 6 . The average species richness (mean number of species for fish specimen) in infracommunity of bleak was $0.51 \pm 0.56$ species. Average abundance (mean number of helminths in fish) in these infracommunities was $1.00 \pm 1.36$. The parasite communities of $A$. alburnus from the Danube River showed Brillouin's diversity index $\mathrm{HB}=0.43 \pm 0.31$ (range 0.20-0.87) (Table 4).

\section{DISCUSSION}

N. skrjabini was reported as a parasite species in Gymnocephalus cernua, $G$. schraetser, Acipenser ruthenus, A. aspius, Gobio gobio, Blicca bjoerkna, A. brama, A. ballerus, Pelecus cultratus, Carassius carassius, Cyprinus carpio, Sabanejewia bulgarica, Sabanejewia balcanica, Sander lucioperca, S. volgense, Perca fluviatilis, Zingel zingel, Z. streber, Gobius 
kessleri (=Ponticola kessleri), Gobius fluviatilis (=Neogobius fluviatilis), Proterorhinus marmoratus, Gobio gobio, Salmo trutta, Pomatoschistus minutus и Neogobius kessleri (=Ponticola kessleri) from Danube River (Margaritov, 1966; Kakacheva-Avramova, 1977; 1983; Atanasov, 2012; Kirin et al., 2013). Nicolla skrjabini was found in bleak from Danube basin (Moravec, 2001). N. skrjabini was found in A. sapa from River Latorica in Slovakia (Oros \& Hanzelová, 2009). Alburnus alburnus from Danube River is a new host for Nicolla skrjabini.

L. intestinalis was found in Scardinius erythrophtalmus from Danube River (Kakacheva-Avramova, 1983) and in Serbian part of the river (Đjikanović et al., 2013). The larval stages of L. intestinalis develop in the body cavity of cyprinids Abramis brama, A. sapa, S. erythrophtalmus, A. alburnus, A. bipunctatus, Gobio gobio, Rutilus rutilus, Barbus barbus, B. m. petenyi, Leuciscus cephalus, L. idus and Phoxinus phoxinus (KakachevaAvramova, 1983). In Bulgaria L. intestinalis was found in A. alburnus from dam lake Iskar, River Shiposhnica and River Palakaria (Kakacheva-Avramova \& Naidenov, 1974; Kakacheva-Avramova \& Nedeva-Menkova, 1978). L. intestinalis was reported as parasite species on bleak from Danube River Basin (Moravec, 2001). A. alburnus from Bulgarian section of Danube River is a new host for $L$. intestinalis.

A. lucii was found in Acipenser ruthenus, Leuciscus cephalus, Abramis sapa, Gymnocephalus schraetser, Benthophilus stellatus, Silurus glanis, Perca fluviatilis, Lota lota and Zingel zingel from Bulgarian section of River Danube (Margaritov, 1959, 1966; KakachevaAvramova, 1977; 1983; Atanasov, 2012). A. lucii was reported for Abramis sapa, $L$. cephalus, R. rutilus, Lota lota, Gymnocephalus schraester, Benthophilus stellatus, Proteoinus marmoratus, Abramis brama, Acipenser ruthenus, Lota lota, Esox lucius, Cyprinus carpio, Leuciscus idus, Tinca tinca, Silurus glanis, Perca fluviatilis, Blicca bjoerkna, Aspius aspius, Barbatula barbatula from Danube Basin (Kakacheva-Avramova, 1983; Moravec, 2001; Cakic et al., 2008; Shukerova et al., 2010). A. alburnus from Danube River is a new host for $A$. lucii.

Intermediate host for A. lucii is Asellus aguaticus, and definitive hosts are fish from Cyprinidae, Salmonidae, Percidae, Anguillidae and other families (Kakacheva-Avramova, 1983).

$P$. laevis was found in A. alburnus from Danube River (Margaritov, 1966; Kakacheva-Avramova, 1977; Atanasov, 2012). Gammarus pulex is an intermediate host of $P$. laevis. Definitive hosts are most often fish from the family Cyprinidae, and less often from families Salmonidae, Percidae, Siluridae etc. (Kakacheva-Avramova, 1983).

C. microcephalum was found in Europe mainly in cyprinids - Cyprinus carpio, Carassius carassius, Leuciscus idus, A. brama, A. sapa and Aspius aspius (Moravec, 1994). C. microcephalum was reported for $C$. carpio and $P$. fluviatilis in the Danube Basin (Moravec, 2001). In Bulgaria it was reported from Lake Srebarna with $C$. carpio (Shukerova, 2006) and P. fluviatilis (Shukerova et al., 2010) as hosts and from Mesta River with its synonym Contracaecum squalii and host $C$. carpio (Kirin, 2001). A. alburnus from Danube River is a new host record for $C$. microcephalum.

During this study of helminth communities of $A$. alburnus five parasite species were found (gastrointestinal). This is comparable to some older studies of 
helminth communities of bleaks from the Bulgarian Danube section, but differs from some more recent studies. In this study of helminth communities of bleak from Bulgarian section of Danube River, the prevalence $(\mathrm{P} \%)$ was $47.25 \%$ which was similar to the established prevalence from Kakacheva-Avramova (1977) of $48.3 \%$, but differs from more recent studies of $A$. alburnus from Bulgarian section of River Danube reporting significantly higher prevalences: $75 \%$ (Kirin et al., 2013) and 71.57\% (Atanasov, 2012). Kirin et al. (2013) reported a single parasite species for bleak (gastrointestinal) in biotope Vetren $-P$. laevis which was reported as $P$. tereticollis, based on the resurrection of the species (Špakulová et al., 2011) and redefined as $P$. laevis based on Perrot-Minnot et al. (2018). Atanasov (2012) reported 5 parasite species from $A$. alburnus from Bulgarian section of River Danube, two of them gastrointestinal Bunodera luciopercae and Pomphorhynchus laevis. Kakacheva-Avramova (1977) reported 9 parasite species from $A$. alburnus, five of them gastrointestinal Allocreadium isoporum isoporum, Caryophyllaeides fennica, Proteocephalus torulosus, Rhabdochona denudata and Pomphorhynchus laevis.

\section{CONCLUSION}

As a result of the investigation of 91 bleak specimens from the Danube River, five gastrointestinal parasite species were established. Such high gastrointestinal parasite diversity and prevalence have not been recorded for a long period of time. Alburnus alburnus from the Bulgarian section of Danube River is a new host for Nicolla skrjabini, Ligula intestinalis, Acanthocephalus luci and Contracoecum microcephalum (larvae). Considering the intermediate hosts of the parasites as well as the differences in the established parasite species in the present and previous studies, it can be concluded that there were changes in the local invertebrate fauna in the studied freshwater ecosystem.

\section{REFERENCES}

Anonymous, 2017. The IUCN Red List of Threatened Species, www.iucnredlist.org (02 August 2017, date last accessed).

Atanasov, G., 2012. Fauna, morphology and biology on the endohelminths of fish from Bulgarian part of the Danube River. PhD thesis, Sofia.

Bauer, O. N., V. A. Musselius \& Y. A. Strelkov, 1981. Diseases of Pond Fish, Legkaya Pishchevaya Promishlenost' Publishers, Moscow (RU).

Bush, A., K. Lafferty, J. Lotz \& A. Shostak, 1997. Parasitology meets ecology on its own terms. Journal of Parasitology, 83, 575-583.

Bykhovskaya-Pavlovskaya, I., 1985. Parasites of fish. Manual on Study, Nauka, Leningrad, p. 121 (RU).

Cakic, P., V. Djikanovic, Z. Kulisic, M. Paunovic, D. Jakovcev-Todorovic \& S. Milosevic, 2008. Occurence of endoparasite fauna in Acipenser ruthenus Linneaus 1758 from the Serbian part of the Danube River. Archives of Biological Sciences, 60, 103-107.

Đjikanović, V., S. Skoric \& P. Cakic, 2013. Representatives of tapeworms (Cestoda) of fishes in Belgrade section of the Danube River. In: Proceedings of the VI International Conference "Water \& Fish", Faculty of Agriculture, Belgrade-Zemun, Serbia, pp. 402-408.

Ergens, R. \& J. Lom, 1970. Causative agents of fish diseases. Academia, Prague, p. 384.

Fröse, R. \& D. Pauly, 2017. FishBase, www.fishbase.org (02 August 2017, date last accessed). 
Georgiev, B., V. Biserkov \& T. Genov, 1986. In toto staining method for cestodes with iron acetocarmine. Helminthologia, $\mathbf{2 3}$, 279-281.

Kakacheva-Avramova, D. \& V. Naidenov, 1974. On Bio Factors for Maintaining the Ligulus Outbreak (L. intestinalis) in Iskar Reservoir.-Excert from CHL, XVII, 73-78 (BG).

Kakacheva-Avramova, D., 1977. Studies on helminths of fishes in the Bulgarian section of the Danube River. Helminthologia, 3, 20-45.

Kakacheva-Avramova D. \& I. NedevaMenkova, 1978. Examination of helminths in fish from reservoir Iskar. II. Helminths of fish from river Palakariya. Helminthologia, 5, 39-46 (BG).

Kakacheva-Avramova, D., 1983. Helminths of freshwater fishes in Bulgaria. Bulgarian Academy of Sciences, Sofia. (BG).

Kennedy, C., 1993. The dynamics of intestinal helminth communities in eels Anguilla anguilla in a small stream: long-term changes in richness and structure. Parasitology, 107, 71-78.

Kirin, D. A., 2001. Helminth parasites of $C y$ prinus carpio (L.,1758) (Osteichthyes, Cyprinidae) from Mesta River. Comptes rendus de l'Académie bulgare des Sciences, 12, 89-92.

Kirin, D., V. Hanzelova, S. Shukerova, S. Hristov, L. Turcekova \& M. Spakulova, 2013. Helminth communities of fishes from the River Danube and Lake Srebarna, Bulgaria. Scientific Papers. Series D. Animal Science. Vol. LVI, 333-340.

Magurran, A., 1988. Ecological Diversity and Its Measurement. Cambridge University Press, London.

Marcogliese, D. J., 2004. Parasites: Small players with crucial roles in the ecological theater. Ecohealth, 1, 151-164.

Marcogliese, D. J., 2005. Parasites of the superorganism: Are they indicators of ecosystem health? International Journal for Parasitology, 35, 705-716.
Margaritov, N., 1959. Parasites of some freshwater fishes. Publishing House NIRRP, Varna (BG).

Margaritov, N., 1966. Helminths of the digestive tract and the abdominal cavity of fishes of the Bulgarian section of Danube River. Bulletin de L'institut de Zoologie et Musée, 20, 157-173 (BG).

Moravec, F., 1994. Parasitic nematodes of freshwater Fishes of Europe. Kluwer Academic Publishers, Dordrecht.

Moravec, F., 2001. Checklist of the Metazoan Parasites of Fishes of the Czech Republic and the Slovak Republic (1873-2000). Academia, Prague.

Oros, M. \& V. Hanzelová, 2009. Reestablishment of the fish parasite fauna in the Tisa River system (Slovakia) after a catastrophic pollution event. Parasitology Research, 104,1497-1506.

Perrot-Minnot, M.-J., M. Spakulova, R. Wattier, P. Kotlık, S. Düşen, A. Aydoğdu \& C. Tougard, 2018. Contrasting phylogeography of two Western Palaearctic fish parasites despite similar life cycles. Journal of Biogeography, 45, 101-115.

Petrochenko, V. I., 1956. Acanthocephala of Domestic and Wild Animals. NAS of SSSR, Moskow (RU).

Polačik, M., T. Trichkova, M. Janáč, M. Vassilev \& P. Jurajda, 2008. The ichthyofauna of the shoreline zone in the longitudinal profile of the Danube River, Bulgaria. Acta Zoologica Bulgarica, 60, 77-88.

Rozsa, L., J. Reiczigel \& G. Majoros, 2000. Quantifying parasites in samples of hosts. Journal of Parasitology, 86, 228-232.

Shukerova, S., 2006. Helminth fauna of the common carp, Cyprinus carpio (Linnaeus, 1758), from the Srebarna Biosphere Reserve, Bulgaria. Scientific articles. Ecology 2006, part 2, 218-223.

Shukerova, S., D. Kirin \& V. Hanzelova, 2010. Endohelminth communities of the perch, Perca fluviatilis (Perciformes, Percidae) from Srebarna Biosphere Reserve, Bulgaria. Helminthologia, 42, 99-104. 
Gastrointestinal helminth fauna and helminth communities of bleak (Alburnus alburnus, L. 1758)...

Špakulová, M., M.-J. Perrot-Minnot \& B.

Neuhaus, 2011. Resurrection of Pompho-

rhynchus tereticollis (Rudolphi, 1809)

(Acanthocephala: Pomphorhynchidae) based on new morphological and molecular data. Helminthologia, 48, 268-277.

Paper received 04.08.2017; accepted for publication 30.11.2017

\section{Correspondence:}

Mariya Chunchukova

Department of Ecology and Environmental Protection,

Agricultural University - Plovdiv,

12 Mendeleev blvd, 4000 Plovdiv, Bulgaria e-mail: m.chunchukova@abv.bg 